\title{
1 Identification and Analysis of Land Use Change in Doha Downtown
}

\section{Neighbourhoods}

Hatem Ibrahim ${ }^{1}$, Ashraf Salama ${ }^{2}$, Florian Widemann ${ }^{3}$, Bassma Aboukalloub ${ }^{4}$ and Reem Awwaad ${ }^{5}$ ${ }^{1}$ Department of Architecture and Urban Planning, College of Engineering, Qatar University, P.O. Box: 2713 Doha, Qatar (Corresponding Author)

Email: hatem_ibrahim@qu.edu.qa

${ }^{2}$ Department of Architecture, College of Engineering, University of Strathclyde-UK

Email: ashraf.salama@strath.ac.uk

${ }^{3}$ Department of Architecture and Built Environment, University of Nottingham-UK

Email: Florian.wiedmann@nottingham.ac.uk

${ }^{4}$ Suhail International Trading and Contracting-Qatar

Email: bassma.eissa@hotmail.com

${ }^{5}$ Seero Engineering Consulting - Qatar

Email: reem.y.awwaad@gmail.com

\section{Abstract}

The Neighbourhood Concept was first introduced in the 1920 s by Clarence Perry. This paper adapts Clarence Perry's Neighbourhood Concept and other neighbourhood planning theories. It studies the land use dynamics of Fereej Abdul Aziz, one of downtown neighbourhoods in Doha. The theory is reinterpreted to study three parameters: physical, mobility, and social aspects. The main objective is to empirically investigate the dynamics of existing land uses of downtown neighbourhoods. The study aims at exploring types of land activities and their existing conditions in the study area. The findings aid in making land use guidelines for the downtown neighbourhoods in Doha taking into consideration preferences of the inhabitants. The study would provide useful insights and efficient planning preferences for land use and how change in Downtown neighbourhoods occurs due to the rapid urban growth not only in Doha but also in other emerging cities. 


\section{Background and Objectives}

Doha as an emerging city has become major business investment hub with unique opportunities to drive economic growth. The dynamics of studying land use will result in new urban forms and new patterns of well-being for people, new patterns of behaviour and resource use and new opportunities ad risks.

Neighbourhoods are the primary urban blocks that make up the city. The grouping and organization of neighbourhoods in relation to streets and public spaces constitute the spatial structure of the city (Marans, 2012; Fincher et. al., 2014). A neighbourhood is a group of people who share services and some level of cohesion in a geographically bounded place. Among three key words defining neighbourhoods (people, place, and cohesion), place is the most noticeable term to distinguish neighbourhoods from other terms like community. Community refers to a group of people with a unity of values, beliefs, circumstances, interests, and culture. This is regardless of geographical boundary (Chaskin, 1998; Keller, 1968). According to Patricios (2002), the "neighbourhood unit is described as a scheme of arrangement for the family life community", where it offers residents a convenient access to the neighbourhood facilities such as schools, parks, shops, and public facilities. Neighbourhoods are communities with a more tangible and geographic concept that is useful for many planning purposes such as analysis, service, delivery, and intervention (Wellman and Leighton, 1979; Forrest and Kearns, 2001; Mullan et. al., 2004).

Neighbourhood planning allows local communities to develop a vision for their neighbourhood and to shape its development and growth. A particular form of social reproduction where human activities include: daily life, social interaction, political and economic commitment, is taking place (Patricios, 2002). Hence, defining the geographical and physical conditions of a neighbourhood provides the foundation for planning and research at the neighbourhood level.

Neighbourhood planning was has evolved since the 1920s after the industrial revolution (Silver, 1985). The Neighbourhood Concept was first introduced in 1929 by Clarence Perry to solve urban issues related to housing and urban centres (Perry, 1929). It was developed from the Garden City theory and from the social reform aimed at adapting population growth in urban centres (Herbert, 
1963; Lawhon, 2009; Dempsey, 2012). The Neighbourhood Concept has considered the accessibility of residents from their houses to schools and community centres (Rohe, 2009; Brody, 2013). It has provided specific guidelines for the spatial distribution of housing, community facilities, retail areas, and streets (Verburg et. al., 2004; Serag El Din et. al., 2013).

The Neighbourhood Concept theory has contributed to improve the standards of developing residential environments and it is based on six solid principles: 1) an institution at the center of the neighbourhood; 2) local shopping areas along the perimeter; 3) area dedicated for parks and open spaces; 4) arterial streets along the perimeter; 5) local street network; and 6) size of the neighbourhood supports its residents, housing, and walkability (Perry, 1929; Choguill, 2008). Depending on the size, level of cohesion, and services shared, neighbourhoods are defined at multiple scales.

Perry's theory had been followed and, in most cases, reinterpreted. Schoenberg and Rosenbaum (1980) have supported Perry's theory in terms of the neighbourhood elements. They have emphasized that a neighbourhood exists if boundaries are identified, a name is associated with the area, an institution is centralized, and neighbours share at least one common tie through a social network or shared use of public space. Wang (1965) has redefined the physical elements of the neighbourhood to include social aspects and the neighbourhood principles has been modified to include: 1) people and environment, 2) street system, 3) institution, 4) shopping centre, 5) housing, 6) recreation, and 7) school. Different people have different sizes of families, incomes, and preferences (Wang, 1965; Delmelle et. al., 2013; White, 2015).

The American Planning Association (2006), classified neighbourhood based on Chaskin (1998) and Suttles (1972), and presented the physical requirements of a neighbourhood into three categories:

Physical closeness of face-block neighbourhoods encourages individual and interpersonal relationships,

- A residential neighbourhood consists of several face-blocks, in which it shares amenities and services to evoke direct participation from residents, 
- An institutional neighbourhood includes several residential neighbourhoods and bounded by official limits of institutions. Its size should allow to accommodate several services and financial institutions.

In Hakim (1986) study, the development of building and urban design principles focused primarily on housing and access. The development was integrated based on Islamic law, and then became semi-legislative in nature. Since building and the development of communities is continuous process, related rules and guidelines were in a demand constantly. Hakim (1986) has incorporated the physical components of downtown area in an Arabic-Islamic city which includes: grand mosque, a government office and a market.

Focusing more on personal relationship and political voice than physical conditions, Jacobs (1961) proposed three levels of neighbourhoods.

- Street neighbourhoods highlight the acquaintances and personal relationships along with streets. Because of overlapping perceptions and personal relationships, the boundaries of street neighbourhoods are not well defined. Even though it was hard to say which level of neighbourhoods is more important, she highlighted street neighbourhoods as the smallest but the most vital and effective self-governing units.

- A large district refers to an area with a recognizable name and consists of 100,000 or more people. Large districts have moderate political power to meet the needs of residents, visitors, and workers.

- The city as a whole is rarely referred to as a neighbourhood. However, she assumed the city would be one of the neighbourhood units having a complete range of services and common interests allowing people to associate with each other. It is argued that bonding to the city, as a whole is the greatest asset.

Land use planning takes into account the physical environment and the social environment where accessible and diverse activities are taking place to enrich the urban living of people (Qaddumi and Ahmadi, 2017). Land use change occurs due to the rapid urban growth in emerging cities. In the case of Doha city, as an emerging city, the land use change is best represented in the downtown 
neighbourhoods which are the early formed neighbourhoods in the center of Doha. The rethinking of the urban structure and land use pattern will enhance the downtown neighbourhoods and firmly will define their role as the premier location for cultural and community living in Doha.

Therefore, the significance of this research lies in the need for a holistic planning process for neighbourhoods which is committed to the planning of Doha. This paper applies Perry's Neighbourhood theory and other pioneers' theories to study the land use dynamics of downtown neighbourhoods in Doha. It is reinterpreted to conclude that physical, mobility, and social aspects are responsible for defining the neighbourhood's land use pattern. The objective of this paper is to empirically investigate the dynamics of existing land uses of downtown neighbourhoods in Doha. Therefore, the parameters that have been implemented from previous studies are defined to include: land use mix and open spaces, accessibility, and housing diversity [Figure 1].

In the Gulf region, the design of neighbourhoods proves the social inference where the fereej (neighbourhood) is the core place for social interaction and bonding. Like other Gulf cities, Doha metropolitan has evolved based on housing agglomerations which have formed unique neighbourhoods around the market and harbour areas [Figure 2, a and b]. In these neighbourhoods, each family built their houses in close proximity to each other, usually wall on wall, due to their strong affiliation and social bonding (Ibrahim, 2013), [Figure 2, c]. This has formed a unique urban fabric for Doha which remained intact until the middle of the twentieth century.

During the second half of the twentieth century, Doha has witnessed its first urbanization period due to the increase of oil production processes. The rapid economic growth has led to the transformation of Doha's built environment. The governmental strategies of economic diversification and living condition improvements were set to build the city image (Hutzell et. al., 2015; Salama et. al., 2017). This has resulted in rapid population growth and high migrants-to-nationals ratio.

The urban fabric of Doha was shaped as a result of landfill policies over recent decades, which has started form the downtown area, forming a radial form of planning. Throughout the years, the planning policies in Doha have been expanding towards the northern and western directions, creating various projects that contribute to the urban development (Nagy, 2008; Murray, 2013; Al Shawish, 
2015). Since the 1960s, urban planning in Doha has envisioned the development of neighbourhoods aiming at creating communities away from the downtown area [Figure 3]. According to Shandas et. al. (2017), the neighbourhoods have been formed based on the planning of the road network. Within the road grids it was anticipated that there would be neighbourhood units. In the north of Doha, a new downtown area has been developed by the government as the premier location for business and highend residential living in the city (Ministry of Municipality and Environment, 2014). It is administered as an expansion of a growing modern city centre.

The downtown area of Doha is the economic, cultural, and administrative heart of the country. This is where urban design and public realm improvements will be undertaken to improve the quality of the living and working environments. Therefore, the downtown neighbourhoods are selected for study based on the following:

- The different development stages that took place during previous decades which have resulted in diverse urban and land use changes in the area,

- The imbalanced demographic structure where migrants are the dominant population in the area, and

- The governmental vision to revive the old center of Doha which plays a major role in enhancing city identity, memory, and belonging.

The rethinking of the urban structure and land use pattern will enhance the downtown neighbourhoods and firmly will define their role as the premier location for cultural and community living in Doha.

The study area of Fereej Abdul Aziz neighbourhood is selected based on: its typical land use pattern of downtown neighbourhoods, demographic structure of migrant population, and governmental vision of retrofitting its physical form. Its urban fabric is expanded to the surrounding downtown neighbourhoods. Fereej Abdul Aziz is located in Zone 14, between the B and A Ring roads within the municipality of Doha. It is located in a central location in the downtown area where significant projects and places are adjacent. Fereej Abdul Aziz is located near popular places with historical and 
national significance, such as Souq Waqif. It is surrounded by Mushiereb and Al Asmakh neighbourhoods from the north, Al Doha Al Jadeeda and Fereej Bin Derham neighbourhoods from the east, Fereej Bin Mahmoud neighbourhood from the west, and Rawdat Al Khail neighbourhood from the south. Several main roads, specifically the A-Ring and B-Ring roads define the neighbourhood [Figure 4].

\section{Methodological Approach}

\section{Research Questions}

The paper presents a contextual analysis to investigate the downtown neighbourhood land use in Doha through answering the following questions: What are the major forces of the real estate market in terms of downtown neighbourhood development? What are the considered factors for improving the downtown land uses? and How the contextual and social aspects of Doha's urban life in downtown neighbourhoods can be enhanced?

In this study, three main research tools were implemented as follows:

- A content analysis of real estate reports and census data based on governmental documents have been reviewed to understand the neighbourhood planning from a governmental point of view. It aims at analysing the changing conditions of the local market, which affects the dynamics of the physical, mobility and social aspects of neighbourhoods.

- An observation survey of Fereej Abdulaziz neighbourhood (physical aspects): which is conducted to investigate the physical features including the activities performed by the residents. Fereej Abdulaziz was observed twice during weekdays and twice during weekends following a defined circulation route, during afternoon and evening times. In the beginning, the observation was dedicated to the investigation of the neighbourhood's perimeter and surrounding boundaries. This has resulted in annotating the external observation route. The next stage of the observation was dedicated to the investigation of the local roads and developments where various features have been recorded and this has resulted in annotating the internal observation route. 
- A questionnaire survey of residents' preferences (social aspects) in Fereej Abdulaziz neighbourhood has been distributed to include 130 residents' samples, where 103 are valid and to be considered in the survey. The survey aims at understanding physical, mobility and social aspects from residents' point of view in neighbourhoods. According to questionnaire survey, expatriates comprise the highest percentage $99 \%$ of the total respondents (Asians, Arabs, and Westerners), while nationals (Qataris) comprise $1 \%$ of the total respondents. Male respondents are more than female respondents $(56 \%$ males and $44 \%$ females $)$. This confirms that the questionnaire data are parallel to Doha's actual population profile in which the majority of population are expatriate males (67\% males and 33\% females), (Ministry of Development Planning and Statistics, 2015), [Table 1]

\section{Historical Background of Fereej Abdul Aziz Neighbourhood}

Fereej Abdul Aziz is one of the early-formed neighbourhoods in the downtown area. It has highdensity housing, cultural, and economic activities. It is comprised of mid to high-rise apartment buildings surrounded by retail activities.

The urban morphology of Fereej Abdul Aziz has evolved combing both organic and grid-like planning. The earliest houses in the neighbourhood were traditional courtyard houses within a closely intertwined network of streets and passageways. The development of Fereej Abdul Aziz has started since the 1950s where few houses were scattered in remote settings (Jaidah and Bourenane, 2009). The demographic rates have increased significantly, streets were constructed to define the perimeter of the neighbourhood, and the initial planning of land parcels has started.

During the 1960s, stand-alone houses have become a popular housing typology. New land uses have been introduced to the neighbourhood, such as commercial, industrial and religious buildings. In the 1970s, high-rise buildings were constructed in the neighbourhood. This period has shown a clear vehicular influence, in which a new requirement for parking spaces has been considered.

In the 1980s, several governmental institutions have evolved as a new land use. Ring roads have evolved defining the boundaries of the downtown neighbourhoods in Doha. Migrants have 
started to inflow in response to the rapid urbanization. New housing typologies have emerged such as apartments and hotels which are defined as multi-family residential.

In the 2000s, local streets are clearly defined, and vacant lands have been utilized as random parking areas. Migrants comprise the highest percentage 89\% of the total population in Doha in 2017 (Snoj, 2017). Since then, almost all of the residents of Fereej Abdul Aziz are migrants. The downtown area has started to be characterized by overcrowding, high number of single male migrants and a predominantly low-income migrant population. Because of the absence of a clear planning vision, the neighbourhood has failed to promote a quality of urban life. Nationals have moved away to settle in suburban neighbourhoods, leaving the downtown with low conditions in terms of physical, mobility and social aspects.

During the 2010s, new governmental projects have started aiming at reviving the downtown area where there was a strong aim to define the character of the city. The concentric urban structure, that dominated the early evolution of Doha, is still visible today forming a key element in the legibility of Doha and its downtown area [Figure 5].

\section{Analysis of Land Use Dynamics in Fereej Abdul/Aziz Neighbourhood}

The following research tools are used: 1) content analysis of real estate data, 2) observation survey, and 3) questionnaire survey of the residents' preferences.

The analysis of real estate data includes reviewing statistical reports of Fereej Abdul Aziz. This tool aims at understanding the land use dynamics from a governmental point of view. These reports contribute in understanding the changing conditions of the local market, which affects the land use dynamics of downtown neighbourhoods over the years.

to investigate the physical features including land uses and activities performed by the residents. The observation has been conducted through a series of visits to explore the physical, mobility, and social aspects of the neighbourhood. Fereej Abdul Aziz was observed twice during weekdays and twice during weekends following a defined circulation route. In the beginning, the observation was dedicated to the investigation of the neighbourhood's perimeter and surrounding boundaries. This has 
resulted in annotating the external observation route. The next stage of the observation was dedicated to the investigation of the local roads and developments where various features have been recorded. This has resulted in annotating the internal observation route [Figure 6]. The observation has been conducted during afternoon and evening times to observe the peak hours of activities.

The survey of residents' preferences is conducted through questionnaires that aid in understanding the land use changes from residents' point of view in downtown neighbourhoods. The questionnaire survey has a total of 103 residents' samples, where migrants comprise the highest percentage $99 \%$ of the total respondents (Asians, Arabs, and Westerners), while nationals (Qataris) comprise $1 \%$ of the total respondents. According to questionnaire survey, male respondents are more than female respondents (56\% males and $44 \%$ females). The selected sample represents approximately the characteristics of the population in Doha, in which the majority of population are migrant males (67\% males and 33\% females), (Ministry of Development Planning and Statistics, 2015).

\section{Analysis of the Physical Aspects: Land Use Mix and Open Spaces}

In reference to the zoning map of Doha in 2008, the residential land use makes-up most of Fereej Abdul Aziz, followed by the commercial land use. Other land uses are planned to provide urban services, such as recreational uses (green open spaces), religious uses (mosques), community centers, and governmental institutions [Figure 7, a]. According to the Ministry of Development Planning and Statistics (2015), the total number of completed buildings in Fereej Abdul Aziz are 475 buildings, in which 442 buildings are residential, 5 buildings are mixed-use (residential and commercial), and 28 are establishment buildings (religious, governmental institutions, etc.)

The 2015 land use of Fereej Abdul Aziz shows that the amount of commercial land uses has increased as compared to the 2008 land use. The increase can be viewed as a result of the government's vision to reinforce the commercial identity of downtown Doha through providing new economic activities (Ministry of Municipality and Environment, 2014). Open spaces have been removed and replaced by residential land uses and community facilities. Residential land uses remained as multi-family residential. The land use of commercial offices has been relocated along the northern and southern sides of the neighbourhood's perimeter, [Figure 7, b]. 
The observation of the existing land uses shows more homogeneity of land use mix in comparison to the planned land use in 2015. Single-family residential (such as villas), and utility land uses (such as the under-construction metro station) have been observed along the perimeter of Fereej Abdul Aziz. Significant types of commercial uses have been also observed such as restaurants and hotels. However, a number of vacant lands exist in the centre and perimeter areas of the neighbourhood [Figure 8].

Fereej Abdul Aziz is characterised by mixed-use commercial frontage in form of shops along the perimeter, and commercial offices on the eastern side [Figure 9, a and b]. Construction sites of new apartment buildings are distributed across the neighbourhood [Figure 9, c]. On the opposite, a number of vacant lands are used as random parking spaces, and as sites for construction wastes in some locations [Figure 9, d]. The northern end of the neighbourhood is a large-scale construction site

for the metro station [Figure 9, e]. Open spaces do not exist, which makes the land use planning inefficient and does not support public activities. Few existing villas represent high quality of housing in the neighbourhood, as compared to the poorly maintained apartment buildings in surrounding areas [Figure 9, f and g].

According to the survey of residents' preferences, it is concluded that $77 \%$ of the respondents prefer to have mix of land uses. A high preference was given to commercial uses, followed by educational and religious uses [Figure 10, a]. In terms of open space preferences, $66 \%$ of the respondents signifies the presence of open spaces in Fereej Abdul Aziz which can be adjusted in the future for an efficient mix of land uses [Figure 10, b]. If provided, open spaces would improve the physical environment in view of three benefits: diversify the land use in which recreational uses would be provided, improve the neighbourhood's climate and ecology, and create an aesthetically-appealing urban environment.

\section{Analysis of the Mobility Aspect: Accessibility}

The accessibility is analyzed based on vehicular, pedestrian, and cyclist movements. The analysis aims at improving local conditions for walking, cycling, as well as facilitating safe access to the neighbourhood facilities (such as shops, mosques, parks) and public transport services. 
Accessibility is determined by attributes of both the activity patterns and the transportation

system in the neighbourhood. The spatial distribution of activities as determined by the land use are important components of accessibility, as well as the transportation system that links these activities. Fereej Abdul Aziz has a network of arterial and local streets. It is surrounded by four main streets that provide direct access to the neighbourhood facilities [Figure 11]. Despite the frequent pedestrian movements in the neighbourhood, streets are designed to support vehicular use only. This results in lack of safety where the majority of residents are pedestrians.

The main type of activity in Fereej Abdul Aziz is commercial transactions and retailing, which defines the main purpose for pedestrians to move between different land uses. The significant presence of pedestrians in the neighbourhood reflects that most of the mobility trips are walking trips. Despite the importance of the pedestrian travel mode, the design consideration for pedestrian facilities across Fereej Abdul Aziz are very minimal. According to the observation survey, vehicles are considered the main mode of travel with a clear absence of pedestrian sidewalks and cyclist lanes [Figure 12, a]. The neighbourhood is, thus, characterized by unsafe street life where pedestrians and cyclists are mixed with vehicles [Figure 12, b]. Consequently, the mobility patterns in Fereej Abdul Aziz need improvement to comfortably accommodate all street users and to support the adjacent land uses [Figure 12, c].

The traditional urban patterns of pedestrian streets (sikka) that reflect the Qatari past, have been lost and replaced by vehicle-dominated streets and indiscriminate parking that create pedestrian barriers which isolate residents from the sense of community [Figure 13]. It has been observed that the streets lack signage system, which affects the neighbourhood's legibility. Therefore, it can be stated that social connectivity and legibility are constrained in most locations.

According to Ministry of Municipality and Environment (2014), higher densities of population have been exhibited within the C-Ring Road, but outside the C-Ring the population densities are far less, with no promotion of mixed-use centers or employment hubs to promote increased densities, accessibility, convenience and vitality. This existing pattern of development has promoted low density 
urban sprawl, which in turn is highly dependent on the private vehicle for access to highly centralized locations of employment, shopping, and public facilities.

Based on the survey of residents' preferences, $50 \%$ of the respondents consider their work travel distance as a significant travel consideration. Therefore, streets connecting work places and houses should be highly accessible. Moreover, diverse modes of travel are preferred to access the different facilities in Fereej Abdul Aziz. The main mode of travel is public transportation $(75 \%$ of the respondents) which implies the need for integrating taxis and public buses in the street network design [Figure 14].

\section{Analysis of the Social Aspect: Housing Diversity}

Housing diversity is a significant social parameter to investigate land use dynamics. It is a mix of housing that supports socially-cohesive communities while enabling efficient urban operation. This is viewed in terms of the income level and age group of the residents as well as housing typologies.

According to Ministry of Development Planning and Statistics (2015), the rapid population growth in Doha is anticipated to continue for the next years where employment growth is expected to increase supporting Qatar's position as a host for the FIFA World Cup 2022. The income level of Fereej Abdul Aziz residents is characterized as low in which $63 \%$ of the respondents earn a monthly salary less than 20,000 Qatari Riyals [Figure 15]. According to Colliers International (2014), an analysis of monthly income levels suggests that the low-income bracket is defined as less than 20,000 Qatari Riyals which affords rental levels between 1,700 and 6,800 Qatari Riyals per month. Housing diversity and affordability is, therefore, considered a critical need for the local residents of the neighbourhood.

According to Ministry of Development Planning and Statistics (2015), Fereej Abdul Aziz has a total of 3,324 housing units in which 40 units are villas, 245 units are Arabic houses (traditional courtyard houses or single-story villas), 2,990 units are apartments, and 49 units are separate rooms as part of establishment buildings. Housing diversity in Fereej Abdul Aziz is represented in the form of mix of apartment typologies. Based on the regulations, the neighbourhood is originally planned for 10stories apartment housing typologies: $20 \%$ studio apartments, $40 \%$ one-bedroom apartments, $30 \%$ 
two-bedroom apartments, and 10\% three-bedroom apartments of the total housing (Ministry of Municipality and Environment, 2014). However, it can be stated that housing lacks a regulated mix of housing typologies.

Similarly, housing availability for the low-income residents is not envisioned where medium to low-quality apartments are dominant. Most of the housing is devalued through neglect, lack of services, and incompatible built form [Figure 16]. The quality of housing is considered low as a result of the random practices of residents. Random gatherings in front of retail shops were observed along the street, which indicates that there is a need for open spaces. The existence of such spaces can provide recreational and aesthetic values to residents as well as serving a variety of psychophysiological values related to neighbourhood attachment and community belonging. This discourages nationals to move back to the downtown therefore limiting future housing diversity and imbalances the demographic structure of the neighbourhood.

According to the survey of the residents' preferences, $48 \%$ of the respondents prefer diverse housing typologies such as villas followed by $26 \%$ for compound apartments. Lifestyle-based housing is preferred through the development of residential compounds where $72 \%$ of the respondents prefer serviced compounds and 28\% prefer high-rise apartments [Figure 17]. Residential compounds provide mixed housing typologies supported by common gathering places where diverse housing attributes can be met, such as typology and cost. Generally, the social environment of the neighbourhood would be revived if diverse housing typologies were accessible to diverse groups of residents.

\section{Reflection on the Land Use Dynamics of Fereej Abdul Aziz Neighbourhood}

The analysis has shown that the land use mix in Fereej Abdul Aziz complies with Perry's Neighbourhood Concept, in which commercial and retail land uses are located along the perimeter (Perry, 1929). Residential and commercial land uses are fairly distributed. However, the lack of open spaces affects the public realm and devalues the quality of the physical and social environments. Fereej Abdul Aziz lacks the existence of an institution at the centre, due to the governmental planning vision of the downtown area as an economic hub for the city. Fereej Abdul Aziz lacks accessibility 
which calls for a significant need for pedestrian, cyclist, and public transportation accessibility, safety, and legibility considerations.

Despite being one of Doha's old neighbourhoods with vibrant commercial activities, Fereej Abdul Aziz lacks basic public realm infrastructures, such as sidewalks, vegetation, street furniture, and designated parking. Based on the questionnaire survey, the physical and mobility aspects of Fereej Abdul Aziz are highly signified, in which $47 \%$ of the respondents prefer location and accessibility considerations. This is followed by the neighbourhood facilities where $20 \%$ of the respondents prefer serviced and facilities-supported living that meets their diverse lifestyles. However, $35 \%$ of the respondents have considered the neighbourhood and neighbours as a not important consideration which reflects the lack of neighbourhood attachment- devalued social aspects [Figure 18].

A proposal is developed to support sustainable neighbourhoods which aims to promote integration of housing, workplaces, shopping, recreation, and community facilities, linked by walking, cycling, and public transportation networks. It integrates the three land use planning approaches (developed by the Ministry of Municipality and Environment, 2008 and 2015 in addition to the edited map by authors based on the observation survey). The land use dynamics are concluded based on the analysis of the physical, mobility, and housing diversity aspects, taking into account the survey of the residents' preferences.

A community center is introduced in the center of Fereej Abdul Aziz to create the base for social gathering and community bonding. Vacant lands in the south, east, and west of Fereej Abdul Aziz have been transformed to green open spaces for recreation and urban revival purposes. Likely, major improvements to the mobility aspect are attempted where accessibility, diversity, and connectivity should be considered. Integration of all modes of transportation are considered for the local street network by applying Complete Streets concept. The social aspect is improved through the provision of affordable lifestyle-oriented housing to insure diversity, accessibility, and equity measures. This can be addressed through the provision of mixed-use residential developments (such as residential compounds) that account for housing preferences and diversity. The suggest proposal is 
attempted for Fereej Abdul Aziz towards a policy-oriented vision to downtown neighbourhood 400 enhancement that serve the country's approach towards urban and community development.

401 The proposal is developed based on the following, [Figure 19]:

\section{Physical aspects:}

403 - The vacant land in the center is replaced with an institution based on users' preferences, such as a 404 community center, a school, a mosque, or any other form of community places. The location of the 405 institution can be in the center, as in Perry's theory, or other location based on the setting of the 406 neighbourhood.

407 - Vacant lands should be assessed by the local authority based on the land use classification to 408 balance and ensure the diversity of land use mix. In the case of Fereej Abdulaziz, a number of 409 vacant lands along the perimeter have been replaced with green open spaces serving as the 410 neighbourhood's pocket parks for recreational and social bonding activities.

\section{Mobility aspects:}

- Implementation of Complete Street concept in neighbourhoods where the different modes of transportation should be integrated (automobiles, pedestrian and cyclists) depending on the need and the size of the streets. Accessibility and safety measures are highly considered.

- Provision of private and public open spaces that are accessible to all residents.

- Provision of car parking and safe access to different buildings within the neighbourhood.

- The metro station is envisioned to provide a transit-oriented improvement and enhanced

\section{Social aspects}

Study of residents' cultural backgrounds and the demographic structure of the neighbourhood.

- Diversity of housing typologies are proposed based on the study of the demographic structure of 422 the neighbourhood. residential compounds. 
- Increase housing affordability to match different cultural backgrounds and income groups available to the community within the zone. Increase a specific housing typology based on residents' preferences.

- Provision of open spaces for recreational purposes and to enhance the social interaction.

\section{Conclusion}

This study emphasizes the importance of investigating the land use dynamics and studies the consequences of land use change in emerging cities. It is essential for policy makers to analyze the changes of land use in order to place decisions that can be support the future circumnutates of a certain context. In the case of Doha city, and like any emerging city, the extensive changes in land use occur as a result of major economic and infrastructural development.

The overall analysis of Fereej Abdul Aziz has led to developing a proposal for downtown land use planning through the analysis of three land use approaches, and the land use parameters that concluded from Perry's theory and other earlier studies. Summaries of the physical, mobility, and social aspects are discussed based on the current realities of urban governance. This is to achieve an improved policy-oriented vision for land use development or enhancement for the downtown neighbourhoods in Doha.

It is concluded that the analysed land use dynamics in Fereej Abdul Aziz have resulted in disjointed built environment. The land use dynamics were ineffective in responding to urban realities, placing more emphasis on the economy and neglecting social and cultural realms of development. Downtown Doha presents challenges that have resulted in an irregular and inadequate public realm. The trend of land use planning in downtown Doha is said to be unregulated as it reflects the preferences of developers and not residents (end-users).

In terms of the physical aspect, the current zoning and development practices promote the domination of single-use commercial corridors, with the existence of significant number of vacant lands. In terms of the mobility aspect, some of the commercial shops are difficult to access by foot or bicycle which are confirmed to be a major mode of transportation. In downtown Doha, a little 
attention is given to the design of neighbourhoods, where there is a lack of connectivity and accessibility. However, a promising governmental attempt highlights the transit-oriented development of the downtown which would fulfill the neighbourhood needs. In terms of the social aspect, the reality shows that real estate developers have focused on quick housing solutions to accommodate the growing, diverse population and less consideration are given to the low-income residents which are the majority of the downtown population. The underpinning of successful planning is to equalize access to housing among different cultural diverse groups. Accordingly, the diversity of the downtown neighbourhood residents requires that planners to consider community and participatory methods, otherwise they risk relying on misconceptions. Advocacy role can be played by real estate experts to encourage an informed public discourse on the development of downtown neighbourhoods in Doha. This can be done by support local mechanisms for community participation such as establishing an urban forum at the neighbourhood scale and launch a public awareness campaign.

The planning approach should play an active role in guiding the neighbourhood through sustainable solutions in terms of economic, social, and environmental expansions, which should be sought jointly and simultaneously through the planning process. This indicates that sustainable development should be an integral part of planning, especially for historical neighbourhoods that are developed to respond to social needs and individual preferences, as in the case of Fereej Abdul Aziz.

The study empirically investigates the dynamics of Doha land use of downtown neighbourhoods as an example of emerging Gulf Cooperation Council (GCC) Cities. It reflects the lesson learned during the analysis and therefore the required actions that help emerging cities in other countries to achieve sustainable development and to deal with challenges of physical, mobility and social aspects. Neighbourhood planning is a process for providing healthy and livable human settlements. It helps in deciding objectives both in quantitative and qualitative terms. It is a setting of goals on the basis of objectives to be pursued and achieved by the administrative authorities. The efficiency of physical and mobility aspects in neighbourhoods depends on actions taken by national, regional and local authorities. The efficiency of social aspects depends on developers who should assess the integration of social aspects into neighbourhood planning and design, with the social and well-being influences on the established plans. Neighbourhoods are dynamic places, where public areas, housing, and mobility all offer unique opportunities for developers. This is to create potential 
positive social impacts and benefits that include strengthening community bonds, enabling access to jobs, and making streets safer for all. The three mentioned aspects are important facilitators for the urban growth and for the sustainable development in emerging cities. In this sense, the article contributes to the understanding of concrete development mechanisms, which are not a derivative from but an integral part of transformation of emerging cities in other countries.

\section{Data Availability Statement}

All data, models, and code generated or used during the study appear in the submitted article.

\section{Acknowledgment}

This paper was made possible by NPRP grant number [NPRP 07 - 960 - 5 - 135] from the Qatar National Research Fund (a member of Qatar Foundation). The findings achieved herein are solely the responsibility of the authors.

\section{References}

Al Malki, A. (2017). Investigating Livability of Mixed-use Neighbourhood Case Study of Najma in Doha, Qatar: A thesis in Urban Planning and Design (master's thesis). Qatar University, Doha, Qatar. Online at: http://qspace.qu.edu.qa/handle/10576/5801

Al Shawish, A. (2015). Evaluating the Impact of Gated Communities on the Physical and Social Fabric of Doha City. Proceedings of the 12th International Postgraduate Research Conference, 6779. Retrieved from: http://www.irbnet.de/daten/iconda/CIB_DC28789.pdf

American Planning Association. 2006. Planning and Urban Design Standards. Hoboken, NJ: Wiley. Brody, J. (2013). The Neighbourhood Unit Concept and the Shaping of Land Planning in the United States 1912-1968. Journal of Urban Design, 3(18), 340-362. DOI: $10.1080 / 13574809.2013 .800453$

Chaskin, Robert J. 1998. "Neighborhood as a Unit of Planning and Action: A Heuristic Approach." Journal of Planning Literature,13 (1): 11-30. 
Chaskin, Robert J. 1998. "Neighborhood as a Unit of Planning and Action: A Heuristic Approach.'” Journal of Planning Literature,13 (1): 11-30.

Choguill, C. (2008). Developing Sustainable Neighbourhoods. Habitat International, 1(32), 41-48. DOI: 10.1016/j.habitatint.2007.06.007

Delmelle, E., Haslauer, E., \& Prinz, T. (2013). Social Satisfaction, Commuting and Neighbourhoods. Journal of Transport Geography, 30, 110-116. DOI: 10.1016/j.jtrangeo.2013.03.006

Dempsey, N. (2012). Neighbourhood Design: Urban Outdoor Experience. International Encyclopedia of Housing and Home, 29-42. DOI: 10.1016/B978-0-08-047163-1.00542-7

Fincher, R., Iveson, K., Leitner, H., \& Preston, V. (2014). Planning in the multicultural city: Celebrating diversity or reinforcing difference?. Progress in Planning, 92, 1-55. DOI: 10.1016/j.progress.2013.04.001

Forrest, R. \& Kearns A. (2001). Social Cohesion, Social Capital, and the Neighborhood. Urban Studies, 38 (12): 2125-43. DOI: 10.1080/00420980120087081

Gillette, H. (1983). The Evolution of Neighbourhood Planning: From the Progressive Era to the 1949 Housing Act. Journal of Urban History, 4(9), 421-444. DOI: 10.1177/009614428300900402

Hakim, B. (1986). Arabic-Islamic Cities: Building and Planning Principles. Kegan Paul International Limites, England: London. ISBN: 0-9683-1842-8

Handy, S. \& Clifton, K. (2001). Evaluating Neighbourhood Accessibility: Possibilities and Practices. Journal of Transportation and Statistics, 67-78.

Herbert, G.(1963). The Neighbourhood Unit Principle and Organic Theory. The Sociological Review, 2(11), 165-213. DOI: 10.1111/j.1467-954X.1963.tb01231.X

Hutzell, K., El Samahy R, \& Himes A. (2015). Inexhaustible Ambition Two Eras of Planning in Doha. Architectural Design, 85(1), 80-91. DOI: 10.1002/ad.1857

Ibrahim, H. (2013). A New Paradigm of Urban Development: Envisioning Sustainable Futures in Qatar. Sustainable Development and Planning, WIT Transactions on Ecology and The Environment, 173, 299-310. DOI:10.2495/SDP130241

Jacobs, J. (1961). The Death and Life of Great American Cities. 
Jaidah, I. \& Bourennane, M. (2009). The History of Qatari Architecture. Skira, Milan.

Keller, Suzanne. 1968. The Urban Neighborhood: A Sociological Perspective. Vol. 33. New York:

Random House

Lawhon, L. (2009). The Neighbourhood Unit: Physical Design or Physical Determinism. Journal of Planning History, 2(8), 111-132. DOI: 10.1177/1538513208327072

Lockerbie, J. (2018). The Old Buildings of Qatar. Retrieved from: http://www.catnaps.org/islamic/islaqatold.html

Marans, R. (2012). Quality of Urban Life Studies: An Overview and Implications for EnvironmentBehavior Research. Procedia - Social and Behavioral Sciences, 35, 922-942. DOI: 10.1016/j.sbspro.2012.02.058

Ministry of Development Planning and Statistics (2015). The Simplified Census of Population, Housing and Establishments, 2015. Ministry of Development Planning and Statistics. Retrieved from:

https://www.mdps.gov.qa/en/statistics/Statistical\%20Releases/General/Census/Population_House holds_Establishment_QSA_Census_AE_2015.pdf

Ministry of Municipality and Environment (2014). Qatar National Master Plan: Doha Municipality Vision and Development Strategy. 1(1). Retrieved from: http://www.mme.gov.qa/QatarMasterPlan/Downloadsqnmp/MunicipalityStrategy/English/Doha\%20Dec\%202017.pdf

Ministry of Municipality and Environment (2015). Archive Department. Doha Satellite Imageries in 1995, 2003, and 2010.

Mullan, Fitzhugh, Robert L. Phillips, and Edward L. Kinman. 2004. “'Geographic Retrofitting: A Method of Community Definition in Community-oriented Primary Care Practices.' Family Medicine 36 (6): 440-46

Murray, M. (2013). Connecting Growth and Wealth through Visionary Planning: The case of Abu Dhabi 2030. Planning Theory and Practice, 14(2), 278-282. DOI: 
562

563

564

565

566

567

568

Nagy, S. (2008). Dressing Up Downtown: Urban Development and Government Public Image in Qatar. City and Society, 1(12), 125-147. DOI: 10.1525/city.2000.12.1.125

Patricios, N. (2002). Urban Design Principles of the Original Neighbourhood Concepts. Urban Morphology, 6(1), 21-32. https://works.bepress.com/nicholas_patricios/15/

Patricios, N. (2002). Urban Design Principles of the Original Neighborhood Concepts. Urban Morphology, 6(1), 21-32.https://works.bepress.com/nicholas_patricios/15/

Perry, C. (1929). The Neighbourhood Unit: from the Regional Survey of New York and its Environs. Routledge/Thoemmes Press. ISBN 04-15160855.

Qaddumi, D \& Ahmadi, A. (2017). Scaling Down Planning in Doha towards the Neighbourhood and its Public Realm. QScience Connect. DOI: org/10.5339/connect.2017.qgbc.2

Rohe, W. (2009). From Local to Global: One Hundred Years of Neighbourhood Planning. Journal of the American Planning Association, 2(75), 209-230. DOI: 10.1080/01944360902751077

Salama, A., Azzali, S., \& Wiedmann, F. (2017). The Everyday Urban Environment of Migrant Laborers in Gulf Cities: the Case of the Old Centre of Doha, Qatar. City, Territory and Architecture, 4(1). DOI: 10.1186/s40410-017-0061-5

Schoenberg, S. \& Rosenbaum, P. (1980). Neighbourhoods that Work. Rutgers University Press, New Jersey, ISBN 0-8135-0901-7

Serag El Din, H., Shalaby, A., Farouh, H., \& Elariane, S. (2013). Principles of Urban Quality of Life for a Neighbourhood. Housing and Building National Research Center Journal, 9, 86-92. DOI: 10.1016/j.hbrcj.2013.02.007

Shandas, V., Makido, Y., \& Ferwati, S. (2017). Rapid Urban Growth and Land Use Patterns in Doha, Qatar: Opportunities for Sustainability. European Journal of Sustainable Development Research, 1(2), 1-13. DOI: 10.20897/ejosdr/70093

Silver, C. (1985). Neighbourhood Planning in Historical Perspective. Journal of the American Planning Association, 2(51), 161-174. DOI: 10.1080/01944368508976207

Skyscraper City (2007). Qatar in the Past Century. Retrieved from: http://www.skyscrapercity.com/showthread.php?t=433902\&page $=2$ 
Snoj, J. (2017). Population of Qatar by nationality. Priya DSouza Consultancy. Retrieved from: http://priyadsouza.com/population-of-qatar-by-nationality-in-2017/

Suttles, G. (1972). The Social construction of Communities. University of Chicago Print. ISBN 9780226781891.

Verburg, P., Nijis, T., Eck, J., Visser, H., \& Jong, K. (2004). A Method to Analyze Neighbourhood Characteristics of Land Use Patterns. Computers, Environment and Urban Systems, 28(1). 667690. DOI: 10.1016/j.compenvurbsys.2003.07.001

Wang, C. (1965). An Evaluation of Perry's Neighbourhood Concept: A Case Study in the Renfrew Heights Area of Vancouver: A thesis in Community and Regional Planning (master's thesis). The University of British Colombia, Vancouver, Canada. Online at: https://open.library.ubc.ca/media/download/pdf/831/1.0104825/1

Wellman, B. \& Leighton, B. (1979). 'Networks, Neighborhoods, and Communities: Approaches to the Study of the Community Question. Urban Affairs Review, 14 (3): 363-90.

White, J. (2015). Future Directions in Urban Design as Public Policy: Reassessing Best Practice Principles for Design Review and Development Management. Journal of Urban Design, 20(3), 325-348. DOI: 10.1080/13574809.2015.1031212 


\section{List of Figures}

621 Fig. 1. Definition of the study parameters based on Perry's Neighbourhood Concept and other 622 pioneers theories.

623 Fig. 2. Evolution of the downtown neighbourhoods of Doha based on the attached housing agglomerations (Source: Skyscraper City, 2007; Al Malki, 2017; Lockerbie, 2018)

Fig 3. Urban evolution of Doha city from 1995 till 2015 (Source: Ministry of Municipality and Environment, 2015)

Fig 4. The location of the study area: Fereej Abdul Aziz neighbourhood in Doha as highlighted (Source: Ministry of Municipality and Environment, 2015 "edited by authors")

Fig 5. Urban evolution of Fereej Abdul Aziz neighbourhood in Doha (Source: Ministry of Municipality and Environment, 2015 “edited by authors”)

Fig 6. Annotated map of the observation survey route in Fereej Abdul Aziz neighbourhood (Source:

Ministry of Municipality and Environment, 2015 “edited by authors")

Fig 7. Land use planning map of Fereej Abdul Aziz neighbourhood (Source: Ministry of Municipality and Environment, 2008 and 2015)

Fig 8. Existing land uses in Fereej Abdul Aziz neighbourhood where land use changes are outlined (Source: Ministry of Municipality and Environment, 2015 "edited by authors based on the observation survey")

638 Fig 9. Significant differences in the land use mix in Fereej Abdul Aziz (Source: the authors based on 639 the observation survey)

640 Fig 10. Residents' preferences in terms of land use mix and open spaces in Fereej Abdul Aziz (Source: 641 the authors based on the questionnaire survey)

Fig 11. Street network in Fereej Abdul Aziz neighbourhood (Source: the authors) 
643 Fig 12. General street life in Fereej Abdul Aziz neighbourhood (Source: the authors based on the

644 observation survey)

645 Fig 13. Vehicle-dominated streets where safe mobility considerations for pedestrians are lost (Source:

646 the authors based on the observation survey)

647 Fig 14. Accessibility preferences in Fereej Abdul Aziz neighbourhood (Source: the authors based on 648 the questionnaire survey)

649 Fig 15. Income level of residents in Fereej Abdul Aziz neighbourhood (Source: the authors based on 650 the questionnaire survey)

651 Fig 16. General housing quality in Fereej Abdul Aziz neighbourhood (Source: the authors based on 652 the observation survey)

653 Fig 17. Housing diversity preferences in Fereej Abdul Aziz neighbourhood (Source: the authors based 654 on the questionnaire survey)

655 Fig 18. Indicators for the land use dynamics in terms of the physical, mobility, and social aspects in 656 Fereej Abdul Aziz neighbourhood (Source: the authors based on the questionnaire survey)

657 Fig 19. The developed proposal for Fereej Abdul Aziz neighbourhood, applicable for Doha downtown 658 land use planning (Source: the authors) 